\title{
DISCUSSION
}

\section{Permeability assessment of some granular mixtures}

\author{
SHUYIN FENG*, PAUL J. VARDANEGA $\uparrow$, ERDIN IBRAIM†, ISWANDARU WIDYATMOKO \\ CHIBUZOR OJUM\|, BRENDAN C. O'KELLY $\|$ and MARIA NOGAL**
}

\section{Contribution by Brendan C. O'Kelly and Maria Nogal}

As part of their paper (Feng et al., 2019), the authors presented the novel application of the grading entropy framework for hydraulic conductivity assessments, along with a model (equation (27)), requiring only the normalised grading entropy coordinates $A$ and $B$ as inputs, for reliably predicting the permeability coefficient $\left(k_{20}{ }^{\circ} \mathrm{C}\right)$ values of 30 compacted, crushed basalt-gritstone gravel mixtures investigated. The discussers note that the gradation characteristics of these gravel mixtures were such that their $B$ values negatively correlate with $A\left(R^{2}=0 \cdot 50\right)$, meaning that the $k_{20{ }^{\circ} \mathrm{C}}$ values could also be reasonably predicted based entirely on their $A$ values, or less reliably based solely on their $B$ values (equations (25) and (26), respectively). Further, considering all 30 gravel mixtures investigated, their reported values of void ratio $(e)$ linearly correlate positively and negatively with $A\left(R^{2}=0.64\right)$ and $B\left(R^{2}=0.53\right)$, respectively. Importantly, the values of coefficients deduced for these various correlations are dependent on compaction level. As such, equations (25)-(27) would generally underestimate the actual $k_{20^{\circ} \mathrm{C}}$ values for the same gravel mixtures placed at lower densification levels (higher $e$ values). In these instances, the inclusion of the $e$ parameter in the model (equation (27)) would seem appropriate, thereby extending its scope and reliability for other field applications (e.g. assessing loosely placed materials as potential drainage/filter media). Therefore, the following regression model is proposed

$$
k_{20}{ }^{\circ} \mathrm{C}=C_{1} A^{C_{2}} B^{C_{3}} e^{C_{4}}
$$

where $C_{1}, C_{2}, C_{3}$ and $C_{4}$ are the fitting coefficients. Note that $C_{1}$ is expressed in the same units as $k_{20}{ }^{\circ} \mathrm{C}$, whereas the other coefficients are dimensionless. This avoids the mathematical and physical inconsistencies discussed in the papers by Castillo et al. (2014a, 2014b).

Towards demonstrating this point, the discussers performed multiple linear regression analysis for the proposed model (equation (28)) utilising the listed $A, B$ and $e$ values for

\footnotetext{
* Department of Civil Engineering, University of Bristol, Bristol, UK (Orcid:0000-0002-3837-6762).

$\dagger$ Department of Civil Engineering, University of Bristol, Bristol, UK (Orcid:0000-0001-7177-7851).

* Department of Civil Engineering, University of Bristol, Bristol, UK.

§ Pavement Engineering, Centre of Excellence for Asset Consultancy, AECOM, Nottingham, UK (Orcid:0000-0003-1252-3979).

\| Pavement Engineering, Centre of Excellence for Asset Consultancy, AECOM, Nottingham, UK

I Department of Civil, Structural and Environmental Engineering, Trinity College Dublin, Dublin, Ireland (Orcid:0000-0002-1343-4428).

** Department of Civil, Structural and Environmental Engineering, Trinity College Dublin, Dublin, Ireland

(Orcid:0000-0001-5405-0626).
}

the various granular mixtures presented in Table 2. Compared to the authors' model (equation (27): $R^{2}=0 \cdot 90$, $n=30, p<0.0001$ ), the analysis for the proposed expanded model with deduced fitting coefficients $C_{1}=662.75 \mathrm{~mm} / \mathrm{s}$, $C_{2}=5.55, C_{3}=-1.32$ and $C_{4}=4.58$ resulted in a slightly better fit $\left(R^{2}=0.96, n=30, p<0 \cdot 0001\right)$. In terms of the adjusted $R$-squared, $R_{\mathrm{a}}^{2}$, which penalises the number of predictors employed in the model, the two-variable model exhibits a value of $0 \cdot 88$, compared to the proposed threevariable model $R_{\mathrm{a}}^{2}$ value of 0.95 , again indicative of the latter model's better fit.

In order to further test the advantage of the proposed expanded model for other soil types (classifications), the discussers employed the same investigative approach in considering the data set comprising $A, B, e$ and $k_{20^{\circ} \mathrm{C}}$ values reported for 20 silty sand and sand materials in the paper by Arshad et al. (2019). Compared to the gravel mixtures investigated by the authors $\left(D_{10}=0 \cdot 72-7.02 \mathrm{~mm}, e=0 \cdot 51-0.85\right.$ and $\left.k_{20}{ }^{\circ} \mathrm{C}=4 \cdot 19-561.20 \mathrm{~mm} / \mathrm{s}\right)$, these sandy soils had particle shape classes varying from angular to sub-angular, $D_{10}=0.01-0.50 \mathrm{~mm}, e=0.32-0.60$ and substantially lower values of $k_{20^{\circ} \mathrm{C}}$ in the range $0 \cdot 0007-3.50 \mathrm{~mm} / \mathrm{s}$. Further, in terms of linear correlation, the $B$ values of these sandy soils only weakly correlated with their $A$ values $\left(R^{2}=0 \cdot 27\right)$, such that when analysed independently, $k_{20^{\circ} \mathrm{C}}$ only weakly correlated with $A$ and $B$. Overall, the same general trends are evident for both Arshad et al. (2019) and Feng et al. (2019) data sets, namely: $\log k_{20^{\circ} \mathrm{C}}$ correlates positively with $\log A$ and negatively with $\log B$, whereas $\log D_{10}$ and $e$ both correlate positively with $A$ and negatively with $B$. In terms of the $k_{20^{\circ} \mathrm{C}}-e$ relationship: for the Arshad et al. (2019) data set, power fitting produced superior $R^{2}$, whereas for the Feng et al. (2019) data set, power and exponential fitting were found to produce comparable results $\left(R^{2} \approx 0 \cdot 86\right)$.

The discussers found that equation (27) cannot reliably represent the described sandy soil data set, with $90 \%$ of the Arshad et al. (2019) points falling outside the prediction intervals $(\alpha=5 \%)$. Further, with fitting coefficient values deduced for the basalt-gritstone gravel mixtures as inputs, the proposed expanded model also cannot reliably represent the sandy soil data set, with $95 \%$ of the Arshad et al. (2019) points falling outside the prediction intervals $(\alpha=5 \%)$. In other words, it would appear that the deduced fitting coefficient values are specific to the particular test material under investigation. This is not unexpected, but consistent with the fact that the two samples (data sets) do not represent the same statistical population.

The discussers also performed multiple linear regression analysis of the data set $(n=20)$ for the silty sand and sand materials to investigate the goodness of fit achieved for both prediction models. Compared to the model without the $e$ parameter included $\left(R^{2}=0.45, R_{\mathrm{a}}^{2}=0.30\right.$ and $p=0.006$ for $C_{4}=0$ ), the proposed model (equation (28)) produced values of $R^{2}=0.68, R_{\mathrm{a}}^{2}=0.56$ and $p=0.0003$. That is, consideration of the $e$ parameter significantly improves the fitting, with less than $50 \%$ of the variability of the data predicted by the two-variable model, whereas equation (28) 
accounts for almost $70 \%$ of the variability of the model. Further, the $k_{20}{ }^{\circ} \mathrm{C}$ values for these sandy soils were mostly captured by $B$ and $e$, whereas $A$ adjusts the final $k_{20^{\circ} \mathrm{C}}$ value (small $C_{2}$ value). Compared to the basalt-gritstone gravel mixtures, the substantially different values of the deduced fitting coefficients and significantly lower $R^{2}$ values for the sandy soils may be explained by greater variation in their gradation characteristics (with $B$ substantially independent of $A$ ), differences in shape factor for the solid particles and their significantly greater specific surface area $\left(S_{\mathrm{s}}\right)$, as well as possibly the relatively small sample size of this data set. As with the evolution of conventional permeability models, the inclusion of a particle shape factor and the $S_{\mathrm{s}}$ parameter in the formulation of the discussed models may further enhance their performance.

\section{Authors' reply}

The authors are delighted by the discussers' interest in the research presented in the paper by Feng et al. (2019). The discussers have proposed an improvement to a regression model, equation (27) (Feng et al., 2019), for the hydraulic conductivity (or coefficient of permeability) which considers the compaction level of soil mixtures (equation (28)). As an indicator for compaction level, the void ratio $(e)$ is now incorporated along with the normalised grading entropy coordinates $A$ and $B$ as predictors of permeability. Equations (27) and (28) were then examined by the discussers using the data set of gravel mixtures from the paper by Feng et al. (2019) $(n=30)$ and the silty-sand and sand materials data set $(n=20)$ from the paper by Arshad et al. (2019). The authors agree that the inclusion of the void ratio $(e)$ does enhance the prediction accuracy of equation (27) to some extent, as illustrated by the discussers in their contribution. This is expected as the void ratio $(e)$ has been long recognised as a primary predictor for coefficient of permeability of soils and soil mixtures and is included in many empirical and semi-empirical models (e.g. Kozeny, 1927; Carman, 1937, 1939; Carrier, 2003; Chapuis \& Aubertin, 2003; Chapuis, 2004, 2012; Vardanega et al., 2017).

The authors have further refined the fitting coefficients $C_{1}$ to $C_{4}$ in equation (28) given by the discussers using the original data files from the paper by Feng et al. (2019), to generate equation (28a)

$$
\begin{gathered}
k_{20^{\circ} \mathrm{C}}(\mathrm{mm} / \mathrm{s})=671.83 A^{5.59} B^{-1 \cdot 30} e^{4.58} \\
R^{2}=0.96, n=30, p<0.0001
\end{gathered}
$$

The slight discrepancy between equations (28) and (28a) (i.e. the values of $C_{1}$ to $C_{4}$ ) is because the data presented in the technical note were rounded to two decimal places to save space. To further illustrate the improvement in prediction of the coefficient of permeability for the data set from the paper by Feng et al. (2019) $(n=30)$ using equation (28a) instead of equation (27), the predicted against measured value plot (Fig. 13) was drawn. Compared to the predicted against measured plot generated using equation (27) (Fig. 12, Feng et al., 2019), it can be seen that a few more points migrate into the $\pm 50 \%$ bounds. The authors therefore agree with the discussers that equation (28a) has better predictive power than equation (27) for this data set. It is also worth pointing out that Fig. 13 has the more points within the $\pm 50 \%$ bounds than shown on Fig. 8 (i.e. for the 'Kozeny-Carman' model (Kozeny, 1927; Carman, 1937, 1939). Therefore, for the data set from the paper by Feng et al. (2019) $(n=30)$ equation (28a) is the most preferred choice (of the models examined) on the basis of both the coefficient of determination values and the number of points falling within the $\pm 50 \%$ bounds on the predicted against measured plots.

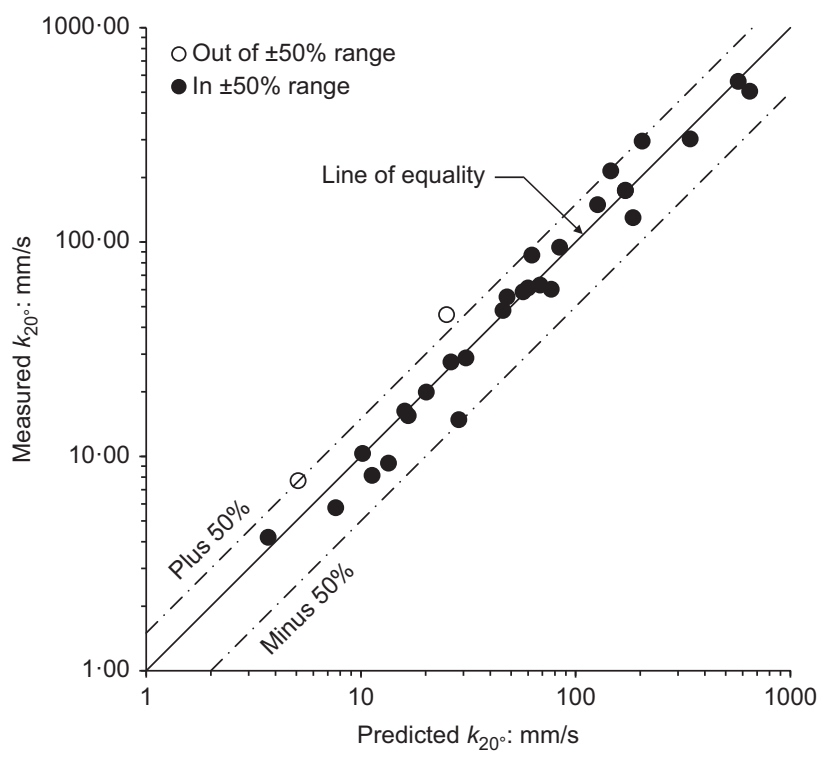

Fig. 13. Predicted $\boldsymbol{k}_{20}{ }^{\circ} \mathrm{C}$ plotted against measured $\boldsymbol{k}_{20}{ }^{\circ} \mathrm{C}$ for equation (28a), calibrated with the data set from the paper by Feng et al. (2019) $(n=30)$

That said, the authors wish to reiterate that the aim of the research presented in the paper by Feng et al. (2019) was to determine whether the normalised grading entropy coordinates alone can be used to give an estimate of the coefficient of permeability of gravel mixtures. Pavement engineers often specify gradation curve envelopes for mixtures when designing such mixtures and therefore a method to estimate coefficient of permeability straight from the gradation curve itself is useful. To this end, equation (27) did not include void ratio: the effect of void ratio having been tested by way of the 'Kozeny-Carman' (e.g. Kozeny, 1927; Carman, 1937, 1939) and Chapuis (2012) formulations (see Figs 7 and 8 ) in the original technical note. However, the authors agree that forms of equation (28) should be considered for future research work in this area.

The discussers also note that equation (27) cannot successfully predict the data set presented in the paper by Arshad et al. (2019) $(n=20)$. As equation (27) is calibrated based on the data of one soil type only, this is not surprising. The authors never suggested that equation (27) was a universal equation for all soils or soil mixtures. As stated in the paper by Feng et al. (2019: p. 653), 'the coefficients and correlations calculated in equations (18)-(27) only hold for the specific soil tested in this research'. With a larger database of more diverse soil types and gradations, the calibrated coefficients of equation (27) may be made more representative. It is good to read that the discussers report similar overall trends for the Arshad et al. (2019) data set as for the data set from the paper by Feng et al. (2019). This further confirms that some degree of correlation exists between the coefficient of permeability and the normalised grading entropy coordinates.

The authors agree with the discussers that inclusion of more information such as specific surface and particle shape factor should improve the correlations. However, as already stated, the authors were attempting to see how well a smaller number of parameters could predict the coefficient of permeability of the gravel mixtures studied.

The authors would like to restate their appreciation to the discussers for their effort in producing equation (28) and re-examining the two data sets presented in the papers by Feng et al. (2019) and Arshad et al. (2019). Drawing predicted against measured plots similar to those shown in 
Fig. 13 for the data set in the paper by Arshad et al. (2019) would be helpful to demonstrate graphically the predictive power of the fittings presented by the discussers.

\section{REFERENCES}

Arshad, M., Nazir, M. S. \& O'Kelly, B. C. (2019). Evolution of hydraulic conductivity models for sandy soils. Proc. Instn Civ. Engineers - Geotech. Engng, https://doi.org/10.1680/jgeen.18. 00062.

Carman, P. C. (1937). Fluid flow through granular beds. Trans. Instn Chem. Engrs 15, 150-166.

Carman, P. C. (1939). Permeability of saturated sands, soils and clays. J. Agric. Sci. 29, No. 2, 262-273, https://doi.org/10.1017/ S0021859600051789.

Carrier, W. D. III (2003). Goodbye, Hazen; Hello, Kozeny-Carman. J. Geotech. Geoenviron. Engng 129, No. 11, 1054-1056, https://doi.org/10.1061/(ASCE)1090-0241(2003)129:11(1054).

Castillo, E., Calviño, A., Nogal, M. \& Lo, H. K. (2014a). On the probabilistic and physical consistency of traffic random variables and models. Comput.-Aided Civ. Infrastructure Engng 29, No. 7, 496-517, https://doi.org/10.1111/mice.12061.

Castillo, E., O'Connor, A. J., Nogal, M. \& Calviño, A. (2014b). On the physical and probabilistic consistency of some engineering random models. Struct. Saf. 51, 1-12, https://doi.org/10.1016/ j.strusafe.2014.05.003.
Chapuis, R. P. (2004). Predicting the saturated hydraulic conductivity of sand and gravel using effective diameter and void ratio. Can. Geotech. J. 41, No. 5, 787-795, https://doi.org/10. 1139/t04-022.

Chapuis, R. P. (2012). Predicting the saturated hydraulic conductivity of soils: a review. Bull. Engng Geol. Environ. 71, No. 3, 401-434, https://doi.org/10.1007/s10064-012-0418-7.

Chapuis, R. P. \& Aubertin, M. (2003). On the use of the Kozeny Carman equation to predict the hydraulic conductivity of soils. Can. Geotech. J. 40, No. 3, 616-628, https://doi.org/10.1139/ t03-013.

Feng, S., Vardanega, P. J., Ibraim, E., Widyatmoko, I. \& Ojum, C. (2019). Permeability assessment of some granular mixtures. Géotechnique 69, No. 7, 646-654, https://doi.org/10.1680/jgeot. 17.T.039.

Kozeny, J. (1927). Über kapillare Leitung des Wassers im Boden (Aufstieg, Versickerung und Anwendung auf die Bewässerung). Sitzungsber. Akad. Wiss. Wien. 136, No. 2a, 271-306 (in German).

Vardanega, P. J., Feng, S. \& Shepheard, C. J. (2017). Some recent research on the hydraulic conductivity of road materials. In Bearing capacity of roads, railways and airfields, proceedings of the 10th international conference on the bearing capacity of roads, railways and airfields (BCRRA 2017), Athens, Greece (eds A. Loizos, I. Al-Qadi and T. Scarpas), pp. 135-142. London, UK: Taylor \& Francis. 